\title{
Study of College English Fast Reading Teaching Based on Schema Theory and Pre-reading Activity
}

\author{
HuangFenfen \\ Nanchang Institute of Science \&Technology, Nanchang 330108, China
}

Keywords: Schema theory, Pre-reading activities, College English, Quick reading, Teaching mode.

\begin{abstract}
English reading comprehension is an important part of college English teaching, but the current teaching situation is not optimistic. In the teaching process of English reading comprehension, there are a series of problems, for example some teachers take the traditional reading comprehension teaching mode, which mainly focuses on the learning and analysis of words and grammar, ignoring the reading strategy, not to achieve a good teaching effect. Because many students have some problems in reading comprehension, so this paper introduces the schema theory in reading comprehension teaching and puts forward the schema structure of students, to activate the existing schema in the student's mind by the pre reading activities. Finally, through the method of experimental teaching, this paper test the effect of the graphics and the pre reading activity, the test results show that this method can effectively improve the students' reading speed, increasing the students' reading interest, so as to improve the ability of reading comprehension.
\end{abstract}

\section{Introduction}

According to the traditional teaching mode of English reading comprehension, reading comprehension is a passive understanding of the content of the article. From 60 years later, people began to realize that this so-called passive process requires active participation of the reader [1-3]. Graphic theory is an important method to reveal the relationship between reading content and reader, graphic is the brain to reproduce the specific content, and it helps to the relationship between various information of understanding the text content and supplement the information that is not mentioned in the article [4-6]]. Therefore, teachers should help students establish and activate the brain's icon, and then through the pre reading activity teachers provide help for the lower level of English reading, to improve the students' reading comprehension ability.

\section{The Current English Reading Teaching Mode and its Existing Problems}

From the current college English teaching situation, the traditional English reading class is mainly vocabulary and grammar teaching and neglect the use of reading strategies, so a lot of students have the lack of vocabulary, grammar knowledge is not solid [7-9]. At the same time, the traditional English reading teaching method is difficult to achieve the ideal teaching effect, and the traditional method only pays attention to the understanding of language and sentence meaning. In the classroom teaching, most of English teaching uses the teaching process as shown in Figure 1.

Figure 1 shows the teaching process of the traditional English reading. In this teaching mode, teachers argue that reading is from the letters to words, and then from the sentence to the whole, finally the process of extracting the text word meaning from the word to sentence. So, the current reading comprehension teaching is the most grammar, sentence and text translation, students waste most of the time in the words, sentences and grammar analysis, and then to recite the text through the translation of the text, finally to carry out spoon feeding teaching. This kind of teaching method ignores the background knowledge of students' reading comprehension, and teachers are one-sided pursuit reading accuracy, so students are a passive acceptance of the status in reading comprehension, resulting in student verbatim reading habits, when there are greater lengths of the text, reading ability will become worse and worse. 


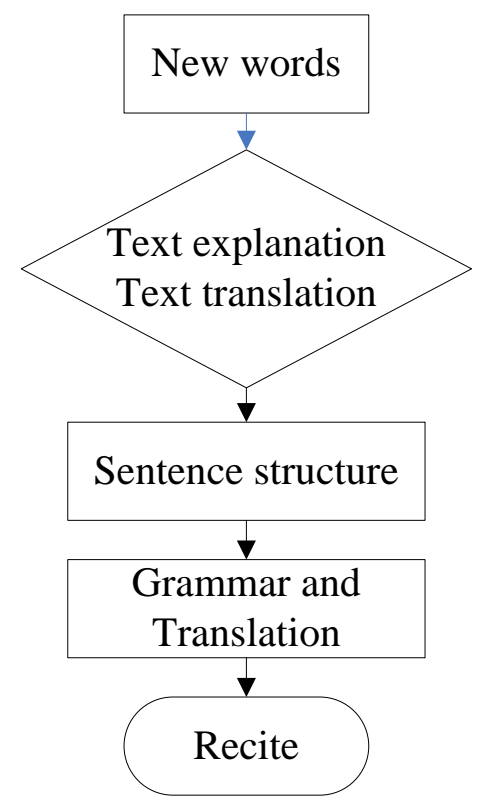

Fig.1 The traditional English reading teaching process

\section{Reading Teaching method based on Schema Theory and Pre reading Activity}

Schema theory was proposed in 1932 by Gestalt psychologist Bart lett, which was mainly study the brain organization and brain storage model, to obtain the further development with the combination of artificial intelligence [10-12]. In the eighty's, the schema theory has become an important part of reading comprehension and discourse analysis, people go through related brain graphics to understand the new words, and then people put forward the interaction between brain graphics and knowledge background in reading comprehension activity [13-15]]. The teaching process based on schema theory and pre reading activity is shown in Figure 2.

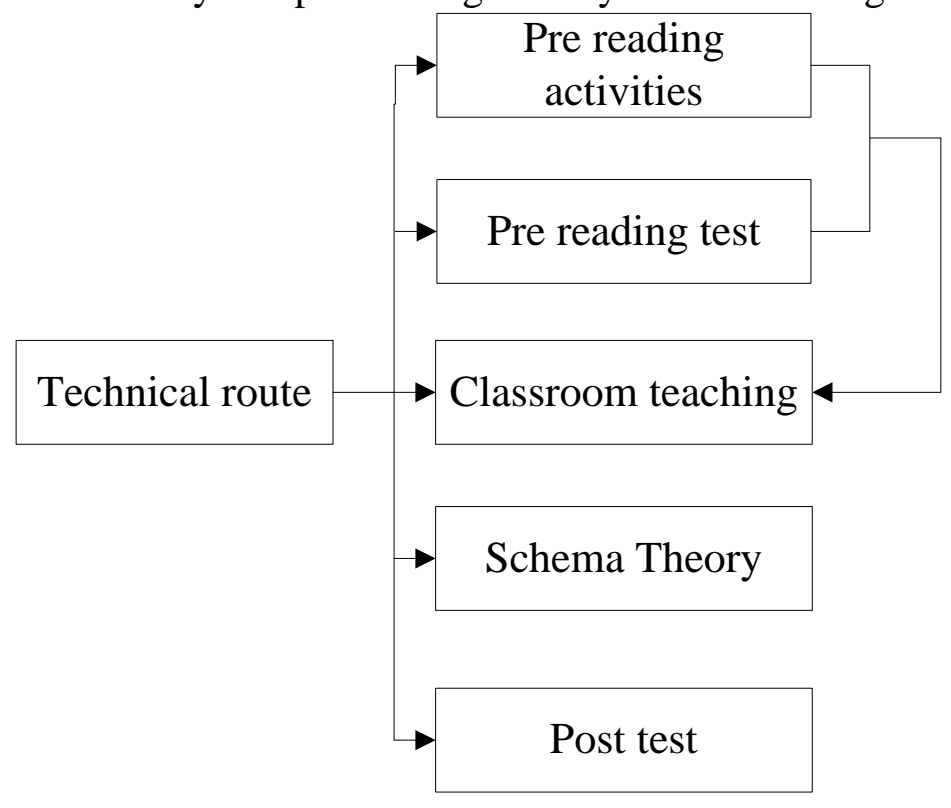

Fig. 2 English fast reading teaching technical route

Figure 2 shows the technical route and process of English reading teaching, this method tests the students' reading before teaching, to understand the actual reading level and the students' reading ability in the traditional teaching mode. Then through the classroom teaching, using graphic theory method carries out teaching activities, to achieve the task English reading teaching based on schema theory. Through a semester of teaching, we can test the effect of teaching, and using the form of questionnaire survey understands graphic teaching method to improve the ability level. 


\section{English Reading Comprehension Teaching Effect Test}

This teaching experiment is one semester, and the teaching method uses pre graphic theory activities task-based reading. After a semester of teaching, this paper test the effect of teaching through the form of questionnaire survey, the test results are shown in Table 1.

Table 1. $\mathrm{t}$ test results before and after total score experiment

\begin{tabular}{|c|c|c|}
\hline Experiment class & Standard deviation & Mean standard error \\
\hline Before experiment & 3.125 & 0.525 \\
\hline After experiment & 3.252 & 0.502 \\
\hline
\end{tabular}

Table 1 shows the $\mathrm{t}$ test results before and after total score experiment, the results show that there are differences among the students' English reading level, so as to verify the validity of the sample selection. Through the paired samples t test, the results are as shown in Table 2.

Table 2. The results of paired samples t test before and after reading achievement experiment

\begin{tabular}{|c|c|c|c|c|c|c|}
\hline \multicolumn{5}{|c|}{ Pairwise difference } & \multirow{3}{*}{$\mathrm{t}$} & \multirow{3}{*}{ Sig. (bilateral) } \\
\hline \multirow{2}{*}{ Mean } & \multirow{2}{*}{$\begin{array}{l}\text { Standard } \\
\text { deviation }\end{array}$} & \multirow{2}{*}{$\begin{array}{c}\text { Mean } \\
\text { standard error }\end{array}$} & \multicolumn{2}{|c|}{$\begin{array}{l}\text { 95\% confidence interval } \\
\text { difference }\end{array}$} & & \\
\hline & & & Lower limit & Upper limit & & \\
\hline-3.28 & 0.92 & 0.15 & -3.28 & -2.68 & -21.28 & 0.000 \\
\hline
\end{tabular}

Table 2 shows the results of reading achievement experiment paired sample t test, it can be seen that through the paired test of independent samples, $t$ value is -21.28 , Sig. (2-tailed) is 0.000 , namely $\mathrm{P}$ value is less than 0.05 , which shows that the results of the students' reading comprehension have obviously different after experiment teaching. Finally, we can obtain the average score of the experiment after the average score is calculated, the average score of reading comprehension before and after teaching experiment is shown in Table 3.

Table 3. The average score of reading comprehension before and after teaching experiment

\begin{tabular}{|c|c|c|}
\hline Experiment class & Number & Reading comprehension average score \\
\hline Before experiment & 58 & 10.28 \\
\hline After experiment & 58 & 13.51 \\
\hline
\end{tabular}

Table 3 shows the average score of reading comprehension before and after the teaching experiment, it the table can be seen that through the experimental teaching, English reading average score increased 3.23 points, students scored the majority of 10-18 points, 20 questions has the majority of 10-18 road.

After teaching experiment, this paper carries out questionnaire survey on the students' reading comprehension. The results of questionnaire survey are obtained as shown in Figure 3. 


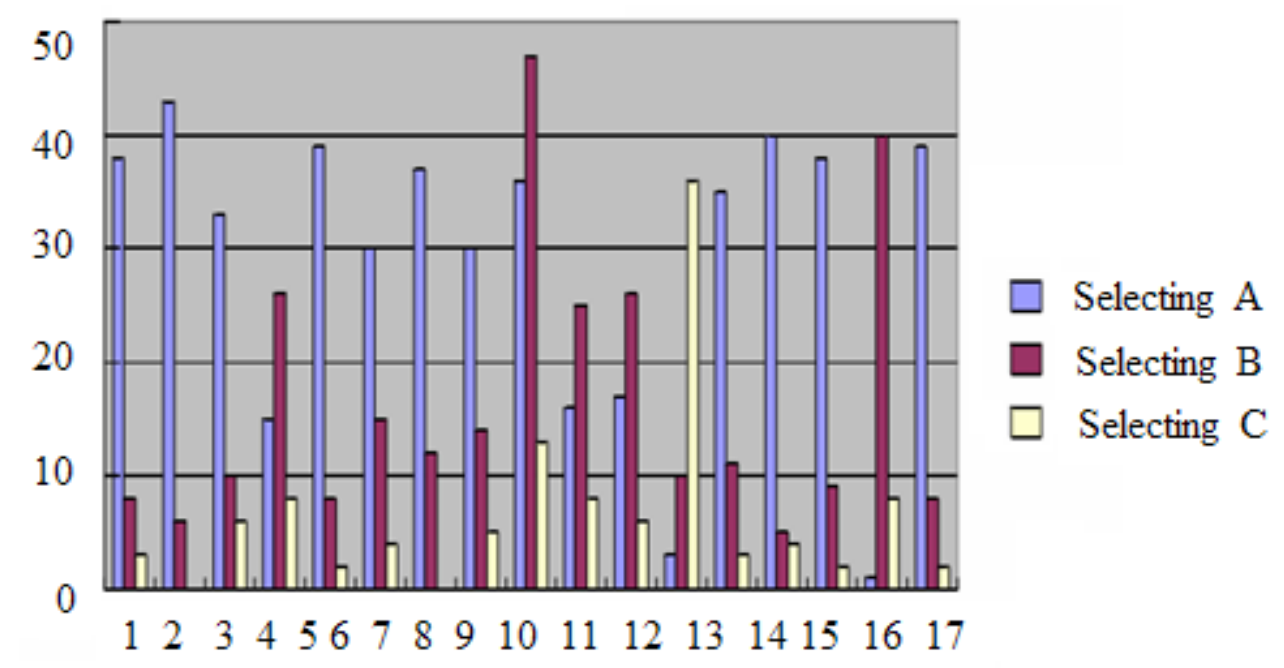

Fig. 3 The results of the questionnaire survey after the experiment

Figure 3 shows the students' questionnaire results after the experiment, in which the horizontal axis represents the question number, and vertical axis represents the number of options. In Figure 3, it can be seen that the first question mainly inspects the student reading speed, the results select the $A$, the speed of reading and comprehension have obviously improved under the role of schema theory and pre reading task driven teaching method; the second question mainly investigate the students' reading interest, the results are the majority of $A$, which means that the method can effectively improve the students' reading interest; the third questions examine the students' reading self-confidence, the results can be seen that the students reading self-confidence has been improved.

\section{Summary}

This paper uses graphic theory and task driven teaching method, to carry out the experimental study of college English teaching. Through the test of one semester, we found that the students' reading speed, reading interest and reading confidence have different degrees of improvement. Although the traditional teaching method can make the students' achievements, the way is to enlarge their vocabulary, to make the reader passive acceptance. Compared with the traditional teaching method, schema theory and task driven teaching method are more effective and feasible.

\section{References}

[1] S.S. Qian. Schema construction and meta cognitive enhancement in college English reading. Frontier economy and culture, 2013(4): 52-54.

[2] F. Wang. The Enlightenment of schema theory on College English reading teaching. Journal of China Petroleum University, 2014(3): 17-19.

[3] C.H. LV, B. Song, Y. Wang. Oral English test score standard comparative study. Foreign language teaching and research, 2013(6): 445-446.

[4] L. Zhang, Z.L. Wen, J.T. Hou. The intermediate effect test procedure and its application. Journal of psychology, 2013(5): 620 -624.

[5] X.D. Zhang. Research on the relationship between vocabulary knowledge and the two language listening comprehension. Foreign language field, 2014(2): 36-42.

[6] X.D. Zhang, Y.H. Chen. The effects of memory components on the two language listening comprehension. Modern foreign languages, 2014(3): 360-369.

[7] J.F. Wang. Application of hierarchical teaching strategies in University Chinese teaching. Chinese education innovation herald, 2013, 47 (1): 66-67. 
[8] Y. Yang. The advantages and disadvantages of multimedia teaching in English teaching. Journal of Jilin radio and television University, 2014(6): 146-147.

[9] Y.H. Zhang. Study on the dynamic evaluation model of web writing teaching in College English. Foreign language circles, 2013(4): 73-81.

[10] X.Q. Wang. Theory and practice of higher mathematics stratified teaching mode. Jilin education, 2013(11): 20- 21.

[11] L.F. Bai, C.Y. Dai. The influence of different levels vocabulary knowledge on reading and writing. Foreign language teaching theory and practice, 2013 (2): 72-78

[12] X. Li. The research on the relationship among vocabulary, vocabulary depth knowledge and language ability. Foreign language teaching and research, 2014(5): 352 -359.

[13] X.F. Han. Analysis of higher mathematics teaching current situation and thinking the stratification teaching. Journal of Lvliang College, 2014, 23(1): 40- 41.

[14] L. Fu. The use of hierarchical teaching in English teaching. Hope monthly, 2013(8): 100-101.

[15] X.Q. Yu. Matthew effect formation and breakthrough in basic education. Teaching and management, 2013(9): 60-61. 